East African Medical Journal Vol. 78 No. 2 February 2001 EMERGENCY PERIPARTUM HYSTERECTOMY

M. H. Sebitloane, FCOG, Consultant, and J. Moodley, MD, Professor and Head, MRC/UN Pregnancy Hypertension Research Unit and Department of Obstetrics and Gynaecology, University of Natal Medical School, Durban, South Africa

Request for reprints to: Dr. J. Moodley, Department of Obstetrics and Gynaecology, University of Natal Medical School, Private Bag 7, Congella, 4013, South Africa.

\title{
EMERGENCY PERIPARTUM HYSTERECTOMY
}

\author{
M. H. SEBITLOANE and J. MOODLEY
}

\begin{abstract}
Background: Emergency hysterectomy in obstetric practice is generally performed in the setting of life-threatening situations.

Objective: To review cases of peripartum hysterectomy in respect of indications, risk factors and complications.

Design: A retrospective study.

Setting: King Edward VIII Hospital, Durban.

Subjects: Seventy one cases of Caesarean and post-partum hysterectomy performed between January 1993 and June 1998.

Results: The rate of peripartum hysterectomy was 1:836 deliveries. Fifty eight per cent of the hysterectomies followed Caesarean section. The main indications for hysterectomy were ruptured uteri, uncontrollable haemorrhage from atonic uteri, sepsis and morbidly adherent placenta. Perinatal mortality was high and there were four maternal deaths.

Conclusion: Peripartum hysterectomy is a necessary life-saving operation. Prevention of complications that give rise to emergency hysterectomy should decrease maternal and fetal morbidity and mortality.
\end{abstract}

\section{INTRODUCTION}

Obstetric haemorrhage is one of the five major causes of maternal deaths in South Africa(1) and much of the morbidity and mortality from this condition is eminently preventable. The main cause of obstetric haemorrhage is ruptured uteri, particularly in developing countries. Although there has been a decline in the incidence of ruptured uteri in the last decade due to the promotion of antenatal care, provision of protocols of management of labour and early recourse to Caesarean section, the clinical impression at King Edward VIII Hospital (KEH), South Africa, is that emergency peripartum hysterectomy is still a commonly practised procedure.

Caesarean hysterectomy was first proposed by Cavanelli in 1786(2), but it was only in 1896 that Storer first performed a Caesarean hysterectomy in a term human pregnancy(3). It has been used as a life saving procedure since that time. Initially, Caesarean hysterectomy was associated with high rates of maternal mortality but the introduction of modern anaesthesiology, potent antibiotics and improved surgical techniques and suture materials has led to a decline in maternal mortality. Caesarean hysterectomy, however, is still associated with significant morbidity. The aim of our study therefore, was to review the hospital records of all patients who had peripartum hysterectomy in the last five and half years (1993 -1998) in order to establish the causes and to propose protocols for management.

\section{MATERIALS AND METHODS}

This was a retrospective study in which hospital records of all patients who had emergency peripartum hysterectomy during January 1993 to June 1998 were reviewed. Demographic data and indications for hysterectomy were analysed. Descriptive studies were utilised and results are presented as frequencies, mean, range and percentages.

\section{RESULTS}

Hospital records of seventy one women who had emergency peripartum hysterectomy during the study period were reviewed. During this period, there were 59,380 deliveries. The emergency peripartum hysterectomy rate was therefore 1:836 deliveries. The demographic data of all patients is shown in Table 1. The mean age of patients was $30(17$ - 45) years, the mean parity was $3(0$ -9) and the mean gestational age was 36 weeks (27 - 42).

Table 1

Demographic data

\begin{tabular}{lrr}
\hline Parameter & Mean & Range \\
\hline Age (years) & 30.1 & $17-45$ \\
Parity & 3 & $0-9$ \\
Gestational age (weeks) & 36.4 & $27 / 40-44$ \\
Birth weight (kgs) & 3.1 & $0.6-4.3$ \\
\hline
\end{tabular}


The indications for emergency peripartum hysterectomy are shown in Table 2 . The commonest indication was ruptured uteri (23/77: $32.4 \%)$. Of these, 19 were found at the time of Caesarean section, performed for a variety of indications as shown in Table 3. Details of six patients who had ruptured uteri following induction of labour are given as follows: (i) twenty four old para 2 had IOL for aproteinuric hypertension at 38 weeks gestation. Prandin gel $\circledast$ was inserted on three occasions, six hours apart. At the next assessment, six hours after the last insertion of prostaglandin, the patient was found to be in hypovolaemic shock, the fetal heart was not heard and the cervix was fully dilated. A laparotomy was performed for suspected uterine rupture, and she delivered $2.75 \mathrm{~kg}$ fresh stillborn; (ii) twenty seven year old para 3 with a post term pregnancy was induced by syntocinon titration intravenously following rupture of membranes, since her cervix was almost fully effaced, and $3 \mathrm{~cm}$ dilated. She progressed to $8 \mathrm{~cm}$ dilatation at which time there were signs of cephalopelvic disproportion. A Caesarean section was therefore performed. An extensive tear of the uterus involving the vagina was found intra-operatively. She delivered a $4.3 \mathrm{~kg}$ live infant; (iii) Twenty eight year old para 2 at term underwent IOL for hypertension. She had two dinoprostone tablet insertions on three occasions, four hours apart. She had a precipitate labour and delivered a $3.2 \mathrm{~kg}$ fresh stillborn, within three hours after last insertion. Labour and foetal heart rate were not monitored and the patient was found to have a defect in the left uterine wall during exploration for postpartum haemorrhage. Hysterectomy was done; (iv) thirty two year old para 2 with an intrauterine death at 27 weeks gestation. She had prior cervical ripening with dinoprostone tablets in the ward. She subsequently had induction with misoprostol

Table 2

Indications for hysterectomy over different time periods

\begin{tabular}{lccc}
\hline Indication & $1993-1995$ & $1996-1998$ & Total \\
\hline Haemorrhage & 13 & 9 & 22 \\
Placental abnormalities & 5 & 4 & 9 \\
Rupture & 10 & 13 & 23 \\
Sepsis & 3 & 14 & 17 \\
\hline Total & 31 & 40 & 71 \\
\hline
\end{tabular}

Table 3

Indications for emergency Caesarean section

\begin{tabular}{lcr}
\hline Indication & No. of patients & $\%$ \\
\hline Fetal distress & 8 & 20 \\
Antepartum haemorrhage & 10 & 24 \\
Failed trial of scar & 2 & 5 \\
Cephalopelvic disproportion & 14 & 34 \\
Rupture & 7 & 17 \\
\hline Total & 41 & 100 \\
\hline
\end{tabular}

tablet $200 \mu \mathrm{g}$. Thirteen hours later the patient was found to have vaginal bleeding with signs of hypovolaemic shock. Laparotomy and hysterectomy were done, and a $600 \mathrm{~g}$ macerated stillborn was delivered; (v) twenty four year old para 1 had IOL for prolonged pregnancy. Contractions started immediately after insertion of $1 \mathrm{mg}$ Prandin gelß and five hours later, she delivered a $3.6 \mathrm{~kg}$ live baby vaginally. She subsequently had postpartum haemorrhage, and on examination, a diagnosis of ruptured uterus was established; (vi) thirty two year para 3 underwent IOL for pre-eclampsia. She had two insertions of Prepidil gelß, six hours apart. She had precipitate labour and advanced from $1 \mathrm{~cm}$ to full dilatation within five hours. She had shoulder impaction and a $3.4 \mathrm{~kg}$ live baby was delivered. Following examination of the genital tract for postpartum haemorrhage, a defect in the left lateral wall was discovered. She had a hysterectomy and; (vii) other indications for peripartum hysterectomy were haemorrhage from atonic uterus $(n=22)$; sepsis $(n=17)$ and morbidly adherent placenta $(n=9)$.

\section{Table 4}

Perinatal outcome per indication for hysterectomy

\begin{tabular}{|c|c|c|c|c|c|}
\hline \multirow[t]{2}{*}{ Outcome } & \multicolumn{5}{|c|}{ Indication } \\
\hline & 1 & 2 & 3 & 4 & \\
\hline Alive & 20 & 9 & 4 & 14 & \\
\hline Stillbirth & 1 & 0 & 16 & 2 & \\
\hline Neonatal death & 1 & 0 & 3 & 1 & \\
\hline Total & 22 & 19 & 23 & 17 & 71 \\
\hline
\end{tabular}

Indication: 1 = Haemorrhage; 2 = Morbidly adherent placenta; 3 = Ruptured uterus; 4 = Sepsis

The perinatal mortality was $24 / 77(33.8 \%)$, with 19 stillbirths and five early neonatal deaths. Most of the stillbirths occurred in women diagnosed to have ruptured uteri (Table 4). The overall maternal mortality rate was $4 /$ $71(5.6 \%)$, the clinical details of these patients are as follows: (a) forty-year old para 4 who had a Caesarean section for foetal distress, had a hysterectomy for uncontrollable haemorrhage secondary to uterine atony. She developed consumptive coagulopathy and renal failure. She spent eleven days in intensive care unit, during which time she had repeated packed cells and platelet transfusions. She died of multiorgan failure; (b) the second and third patients both had hysterectomy because of fulminant sepsis. One of a 26 year old para 2 who delivered at home, and subsequently presented to hospital with puerperal sepsis. Hysterectomy was done on third day after delivery for progressive deterioration in condition. She tested positive to HIV antibodies. The other was a 22-year old para 2 who had a Caesarean section for cephalopelvic disproportion at an outlying hospital. She was referred to $\mathrm{KEH}$ on day five for sepsis and deterioration in haematological investigations. Her HIV antibody status was unknown. Both patients needed intensive care unit 
(ICU) management post-operatively, and despite repeated attempts to correct anaemia and coagulopathy, as well as re-laparotomy for abdominal washout, both subsequently died of sepsis. They spent fifteen and twelve days in ICU respectively; (c) thirty year old para 3 with one previous Caesarean section and laboured at home in the index pregnancy. She presented to hospital with antepartum haemorrhage and emergency Caesarean section was done where extensive uterine rupture was found. After hysterectomy and recovery in ICU, she died eight days later of consumptive coagulopathy, renal failure as well as sepsis. She was HIV antibody positive.

Complications from peripartum hysterectomy are shown in Table 5; and these include febrile morbidity, renal impairment from shock, and sepsis. All except eight patients required transfusion of blood products. Six patients required more than ten units of packed cells. Forty eight per cent required intensive care monitoring immediately post operatively. The mean duration of stay in the intensive care unit was 3.8 days.

\section{DISCUSSION}

Peripartum hysterectomy is generally performed in life-threatening situations and its incidence varies geographically. The incidence quoted in the English literature varies between 1:303 -1:5000 deliveries(4-7). Most reports on peripartum hysterectomy however, are from the Middle East or Asia(6,7). The present study is one of the few from Africa to report on peripartum hysterectomy, and the incidence of 1:836 deliveries places it in the lower ranking of reports on this procedure(8-12). Shava et al(8), in a study at Ga-Ranguwa Hospital, Pretoria, a similar setting as ours, reported an incidence of 1:541 deliveries. Most reports on the causes of emergency hysterectomy in Africa have concentrated on ruptured uteri; in our study, the rate for ruptured uteri was 0.39 / 1000 deliveries. This demonstrates a reduction in the incidence of ruptured uteri at $\mathrm{KEH}$, Durban, as the last report from this centre found an incidence of $1.06 / 1000$ deliveries in 1985(9).

Although the incidence of ruptured uteri is 0.39 per 1000 , this figure did not include women who had ruptured uteri which were repaired. Probably a fairly accurate figure as the policy at KEH in most instances is to perform total abdominal hysterectomy rather than a repair, as advocated by Mokgokong et al(13), except in patients of low parity without evidence of sepsis, and with easily reparable tears in the uterus. The most probable reasons for the reduction in the incidence of ruptured uteri are the provision of community-based obstetric services manned by a specially trained cadre of midwives (the Advanced Diploma Midwives), early detection of cephalo-pelvic disproportion and recourse to Caesarean section, as well as the provision of free maternity care from 1994.

Of the twenty eight cases of uterine rupture, eight (34.8\%) had a previously scarred uterus, whereas in the study by Lachman et al(9) from the same institution in
Durban, this was fifty percent. This figure is still worryingly high as it may reflect that not all patients with previous Caesarean section scars are referred to base hospitals and transport systems may not be adequate. It would appear that more emphasis needs to be placed on educating women with "scarred uteri" of the need for attending antenatal care early in gestation in subsequent pregnancies. In addition, attention needs to be given to community transport systems during the antenatal period. Further, even in this modern age, early admission at 38 weeks should be offered to women who live far from the base hospital, who do not have their own transport and those who are known to be poor antenatal attenders. It is only in this way that we will reduce further the incidence of ruptured uteri.

Of great concern are the six patients who had ruptured uteri following induction of labour. Their mean parity was 2 , and they had no other risk factors predisposing to uterine rupture in labour (such as previous Caesarean section, myomectomy or previous evacuation). Similar cases have been reported in the literature(14-16). In the six cases reported here, prostaglandins were used for induction of labour. Use of such agents need careful monitoring of the foetal heart rate and uterine activity. If continuous electronic monitoring is not available, then "one to one" nursing is imperative as it is not only high risk patients who are likely to end up with hyperstimulation and ruptured uteri, but also low risk patients as demonstrated in our series.

Perinatal mortality from ruptured uteri remains high. In our study, it was $79 \%$, a figure even higher than reported from our centre in the previous study(9). Early presentation of patients to a hospital, as well as high index of suspicion by health care professionals will lead to an increased perinatal salvage rate.

Uncontrollable haemorrhage due to uterine atony was the second commonest indication for peripartum hysterectomy (30.9\%). Other reports have found it to be the leading indication $(17,18)$. Most of these occurred at the time of Caesarean section. As bleeding is usually from the placental bed, hot packs and ligation of identifiable bleeders were employed to control the bleeding, with concurrent use of uterotonic agents like syntocinon infusion and intramyometrial prostaglandin $\mathrm{F}_{2} \alpha\left(\mathrm{PGF}_{2} \alpha\right)$. Bimanual compression and packing of the uterus were also employed in a number of cases. More recently, stepwise devascularisation of the uterus has been recommended(19). Such surgical steps may be time consuming particularly in a patient who is shocked, and may lead to greater morbidity than if a hysterectomy is done immediately following the placing of haemostatic sutures and the application of pressure to stop haemorrhage. This being a retrospective analysis, poor documentation made it difficult to evaluate in detail, procedures performed at the time of operation.

The third commonest cause of emergency hysterectomy in our study was sepsis $(n=17 ; 23.9 \%)$. Shava et al $(8)$ reporting on a similar patient profile, had an even higher figure of $33.3 \%$. Prophylactic antibiotics are 
used in emergency Caesarean sections at our centre, and it is very likely that the progression of sepsis was due to compromised immunity. Ten of the patients with sepsis gave consent for antibody testing to the human immunodeficiency virus (HIV) and nine were antibody positive. The antibody status of the other patients was unknown. This high figure of emergency hysterectomy for puerperal sepsis is of extreme concern as the recent Interim Confidential Report on Maternal Mortality in South Africahas shown that puerperal sepsis is an important cause of maternal mortality and that HIV infection plays a major role(1). Consideration ought to be given to treatment of concomitant genital infections, and prophylactic antibiotic treatment, should probably be used in all pregnant HIV antibody positive mothers. Fifty per cent of the maternal mortality in our series was due to puerperal sepsis.

Most studies on emergency peripartum hysterectomy have found morbidly adherent placenta to be a frequent indication for this procedure(20-22). In our series, this accounted for $12.7 \%$ of cases. This might be due to the fact that sepsis and ruptured uteri are relatively common in our part of the world. Nonetheless steps should be taken to exclude morbidly adherent placenta in patients with placenta praevia and previously scarred uterus, ultrasonically.

The maternal mortality rate of $5.6 \%(4 / 71)$ in our study compares favourably with that of $0-7 \%$ found in other studies $(20,23)$, as does our overall perinatal mortality of $33.8 \%$, where other studies have a range of 24 . $38 \%(6,24)$. Complications from peripartum hysterectomy are high because of the increased blood supply to the pelvic organs during pregnancy, the distorted pelvic anatomy as a result of an enlarged uterus, and the fragile tissue(23). Forty eight percent of our patients had morbidity and this compares well with other studies $(4,17,18)$. The incidence is influenced by many factors including the type of surgery, indication for surgery, the population being studied and the use of peri-operative antibiotics. In our setting, it is routine practice to give prophylactic antibiotics to all emergency Caesarean sections as well as all elective procedures which deviate from normality of plan.

Most of our patients had total hysterectomy which is recommended by most authors(3,4,20,21). Murta et al (25) found that there were no statistically significant differences between subtotal and total hysterectomy regarding operative time, need for transfusion, number of intra and post-operative complications and maternal mortality. In a series by Zelop et al(20), all patients who required a second operation to control vaginal bleeding had subtotal hysterectomy. Other authors have noted long-term complaints of vaginal discharge, acyclic bleeding and the need for cervical cytology associated with subtotal hysterectomy $(4,26)$. In developing countries like South Africa, therefore, where cervico-vaginal infection rates are high and carcinoma of the cervix is the commonest malignancy in the population, total hysterectomy is recommended in such circumstances.

\section{CONCLUSION}

Emergency peripartum hysterectomy is not a rare event. Whilst some of the factors that may precipitate this life-saving procedure may be anticipated, it is not uncommon to have uncontrollable haemorrhage that is not expected. For this reason, all practising obstetricians should be familiar with the technique of Caesarean hysterectomy. Patients at risk of postpartum haemorrhage should have active management of the third stage of labour. Labour should be properly monitored, especially in a patient with previously scarred uterus, who is not only at risk of rupture of the uterus, but also retained placenta which may be morbidly adherent. Patients known to have antibodies to HIV infection should be managed as aseptically as possible, with early use of antibiotics. Caesarean section places these patients at an even higher risk of widespread sepsis, and prophylactic antibiotics should be prescribed. The high incidence of complications in patients undergoing emergency peripartum hysterectomy places a burden on the health sector as a whole. Early involvement of experienced staff in high risk cases should minimise the morbidity from shock and haemorrhage, and the operative complications of an often technically demanding procedure. Finally, all health professionals involved in maternity must be made aware that even in this modern age, induction of labour at term with prostaglandins and is not without complications such as ruptured uteri. Proper and intensive observations must be made available during any induction of labour.

\section{ACKNOWLEDGEMENTS}

To the Chief Medical Superintendent, King Edward VIII Hospital for permission to publish this work.

\section{REFERENCES}

1. The First Interim Report on Confidential Enquiries into Maternal Deaths in South Africa 1997 -1998. National Dept of Health, Pretoria.

2. Durfee R.B. Evolution of caesarean hysterectomy. Clin. Obstet. Gynec. 1969; 12:575-589.

3. Sturdee D.W. and Rushton D.I. Caesarean and postpartum hysterectomy. In: Studd J., ed. Progress in Obstetrics and Gynaecology, Vol 6; Churchill Livingstone, London, 1987 . $195-210$.

4. Clark S.L., Yeh S., Phelan J.P., Bruce S. and Paul R.H. Emergency hysterectomy for obstetric haemorrhage. Obstet. Gynec. 1984;64: 376 - 380.

5. Thonet R.G.N. Obstetric hysterectomy - An 11 years' experience. Brit. J. Obstet. Gynaec. 1986; 93:794 - 798.

6. Aboelmagd M.S., Kaswari R. and Hathout H. Emergency hysterectomy in obstetric practice: 5 year review. Int. J. Gynec. Obstet. 1987; 25 : 437 - 440.

7. Al-Sibai M.H., Rahman F., Rahman M.S. and Butalack F. Emergency hysterectomy in Obstetrics - A review of 117 cases. Aust. N. Z. J. Obstet. Gynaec. 1985; 25: $159-169$.

8. Shava J., Masihleho G.E. and Mazibuko M.D. Peripartum hysterectomy at Ga-Rankuwa Hospital: $\mathrm{a} 2$ and half year review. Cent. Afr. J. Med. 1996; 42:25 - 28.

9. Lachman E., Moodley J., Pitsoe S.B. and Philpott R.H. Rupture of a gravid uterus. S. Afr. Med. J. 1985; 67:333-335. 
10. Amata A.O. Anaesthetic and intensive care management of rupture of the gravid uterus: A review of 50 cases. Trop. Doct. 1998; 28 : $214-217$.

11. Skelly H.R., Dulthie A.M. and Philpott R.H. Rupture of the uterus. S. Afr. Med. J. 1976; 50:505-509.

12. Rendle-Short C.W. Rupture of the uterus in Uganda. Amer, $J$. Obstet. Gynec. 1960; 79: 1114-1120.

13. Mokgokong E.T. and Marivate M. Treatment of ruptured uterus. S. Afr. Med. J. 1976; 50: 1621-1624.

14. Bennett $B$. Uterine rupture during induction of labour at term with intravaginal misoprostol. Obstet. Gynec. 1997; 89: 832 - 833.

15. Phillips K., Berry C. and Mathers A.M. Uterine rupture during second trimester termination of pregnancy using mifepristone and a prostaglandin. Eur. J. Obstet. Gynaec. Reprod. Biol. 1996; 65:175 - 176

16. Zeiger W., Lavenringhao A., Wischnik A. and Melchert F. Uterine rupture without predisposing factors after a single vaginal prostaglandin $E_{2}$ administration in prolonged pregnancy. Zentrablattfur Gynakologie 1995; 117: 51-53.

17. Gurkan Z.C., Turan C., Isik A.Z., Nuri D., Mungan T. and Gokmen O. Emergency hysterectomy in modern obstetric practice: Changing clinical perspectives in time. Acta Obstet. Gynec. Scand. 1998; 77: 186 - 190.

18. Chanrachakul B., Chaturachinda K., Phuapradit W. and Roungsipragarn R. Caesarean and postpartum hysterectomy. Int. J. Gynaec. Obstet. 1996; 54: $109-113$.
19. Abdrabbo S.A. Stepwise uterine devascularisation: A novel technique of uncontrollable postpartum haemorrhage with preservation of the uterus. Amer. J. Obstet. Gynec. 1994; 71: $694-700$.

20. Zelop M., Harlow B.L., Frigoletto F.D. Jr, Safon L.E. and Saltzman D.H. Emergency peripartum hysterectomy. Amer. J. Obstet. Gynec. 1993; $1443-1448$.

21. Mesleh R., Ayoub H., Algwiser A, and Kurdi A. Emergency peripartum hysterectomy. J. Obstet. Gynaec. 1998; 18:533- 537

22. Eltabbakh G.H. and Watson J.D. Postpartum hysterectomy. Int. J. Gynec. Obstet. 1995; 50: 257 - 262.

23. Baclay D.L. Caesarean hysterectomy at the Charity Hospital in New Orleans - 1000 consecutive operations. Clin. Obstet. Gynec. 1969; 12: 635 - 637 .

24. Rachagan S.P. and Sivanesaratinam V. Cacsarean hysterectomy A review of 21 cases in the University Hospital, Kuala Lumpur. Eur. J. Obstet. Gynaec. Reprod. Biol. 1984; 16: 321-326.

25. MurtaF.F., Carneiro J.G. and De Frectas M.M. Total hysterectomy versus subtotal hysterectomy: which procedure should be done during the pregnant-puerperal period? Rev. Pennat. Med. 1993; 111: 354

26. BakerE.R. and D'Alton M.E. Caesarean section birth and Caesarean hysterectomy. Clin, Obstet. Gynec. 1994; 37: 806 - 815 .

\section{EAMJ INTERNET ADDRESS}

"The East African Medical Journal is now available online as well as in print. Subscribers and readers interested in viewing the Internet version may access it using the following address: http://bioline.bdt.org.br/ea

The Online version is distributed by the non-profit service, Bioline Publications, a South/North partnership whose aim is to facilitate global access to bioscience and medical research publications, with emphasis on journals published in the developing world.

Subscription to the online version may be made by completing the Registration Form available from the Bioline home page (http://bioline.bdt.org.br). Readers may take out an annual subscription or purchase single documents. Abstracts are available without registration and free of charge." 